\title{
Ortodoxia y heterodoxia en el FMLN
}

Mayo de 1998 fue el momento en el que la discusión sobre las pugnas en el interior del FMLN alcanzó su punto más álgido. "Ortodoxos" y "renovadores" fueron los calificativos con los cuales la prensa dio a conocer a las fracciones que en el seno del partido debatían acerca del futuro y orientación del mismo. Ya en la Convención Nacional celebrada en septiembre de 1997, la existencia de tal pugna había salido a flote. Pero la polémica en torno a ello se agudizó tras el conocimiento público de un documento anónimo - evidentemente provenicnte de la tendencia "ortodoxa"- denominado Sobre el rumbo actual del FMLN.

Shafick Hándal y Salvador Sánchez Cerén figuraron desde entonces como los líderes de la línea orlodoxa, mientras que Facundo Guardado empezó a ser reconocido como la figura principal del grupo de los renovadores. De acuerdo con la versión de los medios, la pugna emanaba de las FPL - la organización que quedó a cargo de la dirigencia del partido tras la ruptura con el ERP y la $\mathrm{RN}$ - e involucraba, en primera instancia, a Cerén y Guardado. Otras tendencias habrían manifestado su apoyo a una $u$ otra de esas personalidades. Así, Shalick Hándal se habría quedado del lado de Sánchez Cerén, mientras que cfemelenistas como Raúl Mijango -miembro de la Coinisión Política del partido y cabeza de la "tendencia democrática"- y Dagoberto Gutiérrez —ex diputado y líder de la "tendencia revolucionaria"- habrían optado por la propuesta modernizaclora de Facundo Guardado.

La polémica sobre el forcejen en el interior del principal instituto polílico de izquierda fue apaciguándose a la espera de que a éste le llegara la hora de elegir su fórmula presidencial. Y, en efec10 , cse fue el momento en el que las pugnas vieron un nuevo resurgimiento; esta vez con la participación de las bases y con el agravante de que la naturaleza de esa coyuntura la hacía decisiva para los comicios de 1999. La primera - y fallida- Convención Nacional que el FMLN realizara con el fin de elegir a su candidato presidencial puso de manifiesto que las bases habían hecho suyo el conflicto entre ortodoxos y renovadores. Las ofensivas consignas emanadas de los convencionistas y la agresividad e irrespeto de los cuales fue objeto Héctor Silva -en ese momento precandidato de la línea de Guardado-, evidenciaron la virulencia con la que los correligionarios efemelenistas, en especial los del ala conservadora, asumieron la discusión intrapartidaria.

Pero, más allá de los análisis correspondientes a cada una de las situaciones señaladas, cabe observar un poco más de cerca la pugna intestina que ha caracterizado al FMLN, práclicamente desde su inserción a la vida democrática. ¿Quć sc quicre decir exactamente cuando se habla de ortodoxos y renovadores? ¿Se trata de categorías carentes de fundamento, adoptadas por la prensa de manera arbitraria? ¿O son conceptos que reflejan con claridad los problemas internos del Frente? ¿Hasta qué punto los líderes efemelenistas se adscriben conscientemente a una corriente determinada? ¿Existe una discusión ideológica y doctrinal de fondo, o se trata nada más de una lucha de poder cuyo finn último es el control del partido?

Para intentar dar respuesta a estas interrogantes conviene, en primer lugar, aclarar el sentido en el que la opinión pública ha entendido las palabras "ortodoxia" y "renovación" en el caso concreto de esta polémica. Ortodoxos han sido denominados aquellos miembros del FMLN que cuestionan la labor de Facundo Guardado al frente de la Secretaría General, acusándolo de propender a la "dere- 
chización", de olvidar el verdadero horizonte a seguir -el horizonte socialista- y de aceptar postulados del neoliberalismo. Se les llama renovadores a quienes defienden la necesidad de un cambio intrapartidario, que dé lugar a la revisión de sus ejes tradicionales de acción y potencie el diálogo con los distintos sectores de la sociedad.

Ortodoxia se ha denominado, pues, al ala "nostálgica", aferrada a los antiguos lineamientos del marxismo-leninismo, renuente a aceptar las exigencias impuestas por la transformación del país y estancada en la ideología que imperó en la izquierda durante la guerra. La corriente renovadora ha sido, en cambio, identificada con las ideas moderadas, de carácter progresista. Se trata de la tendencia más apegada a la nueva realidad nacional, proclive al cambio y tolerante al diálogo.

Aclarado esto es importante, en segundo lugar, detenerse un poco en el análisis de los textos efemelenistas que han salido a la luz pública. Acerca de Sobre el rumbo actual del FMLN hay que decir que suscribe bien la plataforma ideológica del ala conservadora. No deja de ser llamativo que Sánchez Cerén manifestara su acuerdo con las ideas expresadas allí, pese a haber negado cualquier participación en la redacción del documento. Según el planteamiento de Sobre el rumbo..., la sociedad sólo puede entenderse en clave de lucha de clases, el partido no debe perder su carácter revolucionario y el objetivo de su lucha no ha dejado de ser la instauración de una sociedad socialista. Sc acusa en él a la "nueva corriente" de cosas como querer convertir al Frente en un partido electorero, de avergonzarse de "referirse a las bases y a todo lo que suene a popular" y de avalar la propuesta - a todas luces neoliberal, según su opinión- de las Bases para el plan de nación.

Al calor del debate ocasionado por la salida a la luz pública de este texto, Raúl Mijango publicó en un diario vespertino lo que parecía ser una contestación. Sin embargo, su exposición no guardaba diferencias sustantivas con lo que intentaba cueslionar. Por un lado, Mijango acusaba a ciertos "compañeros" de rencorosos y resentidos por rchusarse a aceptar los cambios que necesariamente deben producirse en el seno de su instituto político. Pero por el otro y paradójicamente sostiene con ellos que el Frente continúa siendo un partido revolucionario, y que su objetivo fundamental no ha dejado de ser llegar al poder con el fin de instaurar un Estado socialista.
"No obstante - agrega el autor-, esto no debe ser el elemento principal de nuestro discurso de hoy, porque ya nos debimos haber dado cuenta que a nuestro pueblo, por hoy, no le interesa mucho que le hablen de ideología, modelos o sistemas; lo que le interesa es ver reflejado en la oferta programática del Partido las soluciones a sus principales problemas y necesidades". De lo que se trata, según Mijango, es de "ganar la confianza de la gente", ese es el "principal reto" del Frente y ese es el punto de partida desde el cual debe entenderse "la inherente necesidad de la continua producción de cambios al interior del FMLN".

Contrastando con las palabras del líder de la "tendencia democrática" se hallan las del "conservador" Hándal en algunos de sus más recientes discursos. Pese a lo que podría pensarse en un primer momento, las ideas de Shafick Hándal enuncian una postura mucho más novedosa y apegada a la etapa de transición democrática por la que atraviesa el país que las manifestadas por el "renovador" Raúl Mijango. Lejos de hacer alusión a un Estado socialista o a un partido revolucionario, la apuesta discursiva de Hándal va dirigida, ante todo, a la institucionalización de la democracia. Más aún, viejas banderas del discurso de derecha - como la insistencia en la modernización del Estado- encuentran acogida en los planteamientos del jefe de la fracción parlamentaria del FMLN.

Nos encontramos, pues, con una suma de ambigüedades, puntos confusos y aparentes contradicciones que se tejen alrededor de la problemática sobre ortodoxia y heterodoxia en el principal instituto político de izquierda. Resulta que Mijango se adscribe a la propuesta renovadora de Facundo Guardado, pero su discurso en tan conservador como el de los más recalcitrantes ortodoxos del partido; que Shafick Hándal es un miembro sobresaliente del bando de los "nostálgicos", pero sus planteamientos son muchas veces más centrados y realistas que los de quienes apoyan la renovación; que Guardado ha evitado a toda costa tomar una postura definida al respecto, pero que con su silencio ha permitido a la opinión pública afirmarse en la idea de que su postura se apega a la heterodoxia; que nadic quiso hacerse cargo de la autoría del revelador Sobre el rumbo... pero que Sánchez Cerén, por un lado, y Dagoberto Gutiérrez —cuya posición es particularmente ambigua - , por otro, acuerpan sus postulados... 
Una explicación posible a la confusión que sin duda, reina en el debate efemelenista, es que esta maraña de epítetos, pugnas, tendencias y acusaciones no tienen nada que ver en realidad con una lucha ideológica intestina, sino que obedece más bien a una mera disputa entre bandos que ansían el control del partido. Tal es la hipótesis del analista político Salvador Samayoa. Para él, quienes se enfrentan por poder en el FMLN lo hacen porque o bien tienen algo que perder o bien algo que ganar en el enfrentamiento. Prebendas políticas y puestos de trabajo son algunos de los ejemplos a los que apeló Samayoa para señalar que las discusiones en el interior de la segunda fuerza política del país no se mueven propiamente en el ámbito de las ideas.

Miope o ingenuo sería no reconocer que algo de csto está presente en el conflicto del Frente. Claro que el enfrentamiento entre distintos "bandos" puede estar animado por la ambición y por el ansia de controlar el partido. ¿Pero es ésta su única fuente? De querer responder afirmativamente a esa interrogante habría que preguntarse primero si acaso no es nalural que los diversos grupos que integran a un instituto político cualquiera rivalicen entre sí y pretendan controlarlo. En eso justamente consiste la política, en luchar por adquirir cuotas de poder lo más significativas que sea posible. Lo interesante no es, pues, detenerse en la observación de los intereses sociales o cconómicos que animan a los políticos - pues la reflexión en torno a ello se ha convertido ya en una verdad de perogrullo-, sino determinar en virtud de qué ideales los partidos y los grupos que los conforman pretenden hacerse del poder, indagar sobre los argumentos de los que se valen para tratar de convencer a sus seguidores de que oplar por ellos es mejor que hacerlo por otros.

En el caso concreto del Frente, está claro que el grupo de los "conservadores" - bajo cuyo mandato se encontraba el partido, antes del arribo de Guardado a la Secretaría General- no está salisfecho con el modo en el que la "nueva corriente" está conduciendo a la institución. Muy fácil resulta adverlir que los ortodoxos desearían recuperar el control del FMLN. Pero las razones que impulsan ese deseo no son sólo los pucstos de trabajo o los demás beneficios que puedan obte- nerse de ello, sino también $-y$ esto no debe soslayarse- la convicción de que ellos son los portadores legítimos de los lineamientos que debe seguir el más influyente instituto político de oposición y que, por tanto, con Guardado al mando, el partido no está en buenas manos.

Demasiado simplista sería, pues, reducir el problema de las pugnas intestinas en el Frente a un interés de predominio sin más. Probablemente es la confusión que ha persistido alrededor del debate lo que ha alimentado esa hipótesis. Pues bien, cabe ahora hacer una aclaración importante con el fin de contribuir a desenvolver la madeja que se ha venido tejiendo en tomo al FMLN. Muy característico de la polémica que nos ocupa ha sido ver en lo pragmático un sinónimo de lo revisionista o lo moderado, cuando en realidad el pragmatismo muy poco tiene que ver con las convicciones ideológicas de los cuadros o de las tendencias. Así, por ejemplo, una de las personalidades del partido puede caracterizarse por su habilidad para dialogar, llegar a acuerdos y conseguir favores o beneficios - lo cual lo convertiría en pragmático-, sin que ello signifique en lo absoluto que pretenda abandonar sus ideas tradicionales, por más retrogradas y cuestionables que éstas sean.

Este es el caso, entre muchos otros que podrían citarse, de Mijango, quien discursivamente defiende la revolución, sostiene que ésta se libra ahora en el terreno de la política y abandera la vieja idea de conquistar el Estado para instaurar, paulatinamente, el socialismo, pero en la práctica opta por el renovador Guardado, quien parece coincidir muy poco con estas formulaciones. No pueden conocerse a ciencia cierta las razones por las cuales 
el líder de la "tendencia democrática" eligió la corriente renovadora. Como sea que haya sido, no es difícil suponer que tal alianza obedece a razones pragmáticas. Y ese mismo pragmatismo es el que serviría para paliar las contrariedades que aflorarían en caso de que el FMLN alcanzara el poder.

Es obvio que constantemente tendrían que llegar a acuerdos quienes conciben al Frente como Él Partido —con mayúscula - responsable histórico de representar a las mayorías populares y obligado, por tanto, a iniciar la transformación estructural de la sociedad - lo cual resulta, por lo demás, incompatible con el juego democrático que limita la permanencia de un mismo instituto político en el Gobierno- con quienes, en cambio, piensan que el FMLN es simplemente un partido entre los demás, al cual corresponde llevar a cabo reformas en el sistema que favorezcan a los más necesitados y modifiquen las condiciones socioeconómicas que posibilitan la injusticia.

También convierte en pragmático a Mijango manifestar la inconveniencia de expresar a las bases lo que concierne a ideologías y sistemas, al aducir que a éstas "no les interesa mucho por hoy" la referencia a tales temas. Eso equivale a proponer que, para ganar la confianza de las bases, es preciso omitir las verdaderas intenciones del Frente y hablar sólo de lo que éstas quieren oír, lo cual recuerda los principios más ortodoxos del marxismo-leninismo, según el cual es el partido el que decide lo que conviene a la mayoría, es su representante liel y, por tanto, sabe qué es lo mejor, aunque no lo consulte con ella.

Vayamos ahora al caso contrario: un efemelenista pucde haber abandonado muchos de los viejos dogmas de la izquierda, puede concebir al partido como uno más entre otros, puede ver posibilidades de gobernar desde el sistema impcrante, puede ser, en fin, un "renovador" $y$, sin embargo, no contar con ninguna habilidad en virtud de la cual pueda llamársele pragmático. Más aún, son los ortodoxos los que están más obligados a desarrollar habilidades que les permilan manejarse en el terreno de la práctica, justamente porque sus ideas son más rígidas, más difíciles de adaptar a cada circunstancia concreta. De no poseer destreza al enfrentar las situaciones quc constantemente exigen sacrificios y ponen a prueba el "compromiso" de un ortodoxo, éste corre el grave peligro de ser calificado como traidor, revisionista u otros de estos calificativos que a la sazón resultan poco menos que insultos.

De lo que se trata, pues, es de entender que ha existido una confusión en los niveles en los que se ha desarrollado la disputa en el interior del FMLN. Una cosa es el debate ideológico -que se mueve en el campo de las ideas y tiene relación con los principios doctrinarios, con las concepciones de Estado, partido, democracia, revolución-y otra distinta es la discusión que se inserta en el terreno de la práctica - que tiene que ver con la habilidad de los cuadros o de las tendencias para enfrentar situaciones concretas, para tomar las decisiones inmediatas que requiere la cotidianidad.

Por razones prácticas, abocados a un hecho en concreto, un ortodoxo y un renovador pueden llegar a la misma decisión. Eso no hace al primero menos conservador ni al segundo más revisionista o más moderado. En lo que posiblemente diferirán será en el modo de concebir la acción. Si es una concesión de algún tipo, el dogmático la asumirá como un sacrificio por llevar a cabo; para él la acción será penosa. El renovador, en cambio, verá tal acción como parte del juego político y entenderá, sin mayor preocupación, que como partido inserto en la vida democrática debe hacer concesiones de vez en cuando.

¿Qué se puede concluir de todo esto? En primer lugar, que es claro que las pugnas intestinas en el Frente han dado lugar a una confusión de la que los mismos efemelenistas parecen ser partícipes y potenciadores. Ha sido un error pensar que ortodoxos son los que siguen a Sánchez Cerén y heterodoxos los que acompañan a Facundo Guardado. La ortodoxia y la heterodoxia no se caracterizan por las personas que se hacen llamar tales, sino por los ideales políticos que persiguen. Además, es importante señalar que tanto en la postura conservadora como en la renovadora existen dislintos matices.

Así, no se puede equiparar el conservadurismo de, por ejemplo, Shafick Hándal -quien entiende el socialismo como un horizonte, como una meta por conseguir en un plazo indefinido- con el de quienes dieron vida a Sobre el rumbo actual del FMLN -cuyo discurso es tan dogmático y panfletario que difícilmente ameritaría ser tomado en serio-; ni puede equipararse la posición de Guardado -quien hizo lo posible por minimizar al máximo la importancia de ese documento- con la de Dagoberto Gutiérrez -quien, en su momento, 
avaló el esfuerzo de los redactores del mismo. En cualquier caso, no hay que perder de vista que la discusión sobre conservadurismo y modernización se juega en el terreno ideológico. En el campo de la práctica intervienen vicisitudes o emergencias que dan lugar a tipos de comportamiento muy variados y que, por consiguiente, no pueden siempre tomarse como afirmación o negación de la identidad ideológica de determinado militante o de determinado grupo.

En segundo lugar, de más está decir que al FMLN le convendría poner en claro los términos de sus disputas. La polémica doctrinaria probablemente nunca desaparezca del todo y debe ser entendida en el marco de los debates que actualmente caracterizan a la izquierda en todo el mundo. Las preguntas acerca del papel que debe jugar la izquierda hoy en día, acerca de cuál debe ser su propuesta alternativa, encierran gran complejidad y con seguridad darán lucha para rato. Pero los forcejeos por el predominio en el interior del partido deberían resolverse mediante la apelación a las preferencias de las bases y el respeto hacia los mecanismos de democracia interna con los que se rige el Frente. En más de una ocasión se ha visto que el hacer uso de los dogmas para exaltar los ánimos de las bases y favorecer a una u otra tendencia, lleva a situaciones caóticas y políticamente perjudiciales.

Debido a la confusión que se gestó en torno a las disputas en el interior del partido, el FMLN está viendo drásticamente disminuidas sus posibilidades de triunfar en los comicios de 1999. Quizás el precio que tendrá que pagar por haber evitado hacer frente a una situación que explotó, sin que los líderes efemelenistas quisieran sentirse afectados, puede ser alto. Eso y la mínima dosis de responsabilidad que cabría exigir al Frente para con sus correligionarios y simpatizantes, debería bastar para que la segunda fuerza política del país decidiera enfrentar, de una buena vez, el problema de sus pugnas internas.

\section{Carmen Elena Villacorta Zuluaga}

